Military Technical College Kobry El-Kobba

Cairo, Egypt

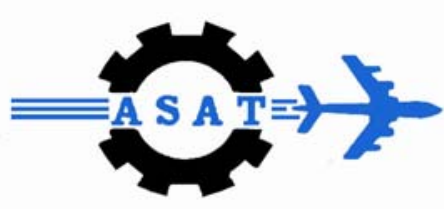

12-th International Conference on

Aerospace Sciences \& Aviation Technology

\title{
AN OVERVIEW OF SOLID PROPELLANT COMBUSTION MODELING
}

\author{
$\operatorname{HEGAB}^{1 *}$ A. M.
}

\begin{abstract}
An overview of theoretical and experimental work concerning the burning process in rocket propellant is presented. The current study has emphasized Ammonium Perchlorate (AP) / Hydroxyl Terminated Poly-Butadiance, (HTPB) composites rocket propellant. These propellants are widely used in a variety of rocket systems ranging from small tactical missiles to the large boosters that propel the space shuttle into orbit. A detailed review for the chemical kinetics, numerical and experimental models for the burning of the monomodal, bimodal, and multimodal propellants is introduced. Effects of propellant compositions, time-dependent pressure fluctuations, temperature, fuel-binder types, on the burning rate are reviewed and discussed. The result of the current study shows the effect of pressure and the AP particle sizes on the burning rate, the complex flame structure, and the morphology of the combustion surface.
\end{abstract}

\section{KEY WORDS}

Composite propellant, solid particles, spheres and discs packing, sandwich propellant, AP/HTPB.

\section{NOMENCLATURE}

$\begin{array}{ll}\text { AP } & \text { Ammonium Perchlorate } \\ A_{A P, B} & \text { Reaction rate constant } \\ B & \text { Binder } \\ \text { BDP } & \text { Beckstead, Derr, and Price kinetics model } \\ C_{p} & \text { Specific heat }\end{array}$

1* Associate Professor, Dpt. of Mech. Power Engineering, Faculty of Engineering, Menoufia University, Shebin Elkom, Egypt. 


$\begin{array}{ll}D & \text { Diffusivity } \\ \mathrm{D}_{a} & \text { Damkohler number } \\ \mathrm{E} & \text { Activation energy } \\ \mathrm{HTPB} & \text { Hydroxyl Terminated Poly-Butadiance } \\ \mathrm{HMX} & \text { Cyclo-tretra-methyle-netetra-nitramine } \\ \mathrm{HMDI} & \text { Hexa-methylene diisocyanate } \\ \mathrm{L} & \text { Characteristic lengths } \\ \mathrm{M} & \text { Mach number } \\ \mathrm{m} & \text { Mass flux } \\ \mathrm{P} & \text { Pressure } \\ \mathrm{Pe}_{\mathrm{e}} & \text { Peclet number } \\ \mathrm{PBD} & \text { Price-Boggs-Derr } \\ \mathrm{PBAN} & \text { Poly-Butadience-Acrylonitrile-Acrylic acid } \\ \mathrm{Q}_{\mathrm{g}} & \text { Heat of reaction } \\ \mathrm{r}_{\mathrm{b}} & \text { Burning rate } \\ \mathrm{R}_{\mathrm{r}} & \text { Reaction rate } \\ \mathrm{t} & \text { Time } \\ \mathrm{T} & \text { Temperature } \\ \text { TFH } & \text { Tetra-hydro-furan } \\ \mathrm{V} & \text { Injected gas velocity } \\ (\mathrm{u}, \mathrm{v}) & \text { Velocity components } \\ (x, y) & \text { Coordinates } \\ \mathrm{X}, \mathrm{Y} & \text { Mass fractions of AP and binder } \\ \text { GREEK SYMBOLS }\end{array}$

$\beta$

$\eta$

$\lambda$

$v$

$\rho$

$\varepsilon$

$\psi$

$\phi$
AP/binder stoichiometric ratio

Surface function

Heat conductivity

Fractional binder thickness

Density

Hill height or valley depth

Function negative in binder, positive in AP

Equivalent ratio

\section{SUBSCRIPTS}

$\begin{array}{ll}\text { AP } & \text { Ammonium Perclorate } \\ \text { B } & \text { Binder } \\ \text { g } & \text { Gas } \\ \text { s } & \text { Solid }\end{array}$




\section{INTRODUCTORY REMARKS}

The designers of solid propellant rockets are still facing several technological problems. These problems require expertise in several diverse research areas. On the other hand side, in order to have a stable engine with high performance, the detailed whole-system simulation of the solid rocket motors must be achieved first. The entire integration must include the modeling of; (1) the ignition and combustion of composite energetic materials, (2) the solid mechanics of the propellant, (3) the case and insulation, (4) the nozzle and the fluid dynamics of the interior flow and exhaust plume, (5) the shock physics and quantum chemistry of energetic materials, $[1,2]$.

These models are characterized by very high energy densities, extremely diverse length and time scales, complex interfaces, reactive, turbulent, and multiphase flows. These complexities are still a big challenge to perform the whole system simulation. As a result, most of the research studies within the last three or four decades have been conducted to examine some of these models separately in order to acquire some information about the complex flame structure and the nature of the generated flow field inside the solid rocket motor chamber.

The coupling and feedback between the pressure oscillations and the burning rate can lead to instability, called "combustion instability",[2]. In another word, the burning rate increases with the chamber pressure, and the chamber pressure increases with the burning rate. For example, a crack in the propellant causes an abrupt change in the surface area, and hence in the burning rate, which in turn causes an abrupt change in the pressure. Pressurization of the crack causes it to grow rapidly and may be the burning reach to the rocket casing in very short times through the crack causing a catastrophic failure for this reason, relatively small defects can lead to catastrophic failure such as the famous Challenger accident many year ago. For further information about the combustion instability, see Ref. [3,4,and 5]. Generally, the origin of the instability in the operation of Solid Rocket Motor(SRM) is probably associated with combustion process of the heterogeneous propellant. The burning of the solid propellant of energetic materials, it is our believe, is the back-pone for the whole system simulation, since it is the deriving thermo-mechanical force in the operation of a solid rocket motor.

As a result, the objective of the current review is concentrated on a model of the solid rocket motor propellant combustion which play an important roles in the dependence of the burning rate on pressure. Rocket propellants may be divided into two general classes, double-base propellants and composite propellants. The principle components of the double base propellants are nitrocellulose and an explosive plasticizer, usually nitroglycerin, [6-9], while the composite propellants are made by embedding a finely divided solid oxidizing agent in a binder. Regarding the latter composite propellant, oxidizing agents which have been used extensively include ammonium nitrate, sodium nitrate, potassium nitrate, ammonium perchlorate, and potassium perchlorate. The materials which 
have been employed as binders are, asphalt, natural and synthetic rubbers, vinyl polymers, polyesters, and nitrocellulose. Ammonium picrate, carbon black, and aluminum powder have been used as fuel fillers [10].

The current review and our recent studies has emphasized the composite propellants because they have been of greatest general interest over the modeling time period. The modern rocket composite propellant mixture consists of the following ingredients[11]; an Ammonium Perchlorate (AP) (oxidizer, 69.6 percent by weight), aluminum (fuel, 16 percent), iron oxide (a catalyst, 0.4 percent), Hydroxyl Terminated Poly-Butadiance, (HTPB) fuel binder (a binder that holds the mixture together, 12.04 percent), and an epoxy curing agent (1.96 percent). AP, $\mathrm{NH}_{4} \mathrm{ClO}_{4}$, based composite propellants are widely used in a variety of rocket motor systems ranging from small tactical missiles to the large boosters that propel the space shuttle into orbit. The properties used for AP come from Tanaka and Beckstead $[12,13]$ and Guirao and Williams [14 10] and the JANNAF tables, [ 8 ]. Most of the thermodynamic and transport properties used for HTPB come from the work of Parr and Hanson-Parr [ adapted from 12], Jeppson et.al. [13], W. Cai and V. Yang [15].

Theoretical and experimental studies of heterogeneous propellant combustion have a long history, much of it from the days when computational and experimental resources were primitive, which encouraged the development of grossly simplified models. Modeling of the combustion of a rocket composite propellant is more complex than that of a single component monopropellants.

To describe the complex gas phase flame structure, many assumptions about the components (fuel + oxidizer) in the system have been made. That is weather these components are mixed before combustion (premixed flame), or weather the two components must first diffuse together before the combustion can take place (diffusion flame). The following models have been adopted to furnish the baseline for the complex flame structure.

\section{CHEMICAL KINETICS MODELS}

During the 1960's, 70s and into 80s, several models have been proposed to describe the combustion of composite propellants. In general these models have been somewhat successful in correlating experimental data, but are not sufficiently accurate, or complete to predict burning rate behaviour. Only the work by Hermance in 1966, [15] considers the combustion problems over a broad range of pressure. Of coarse, like other models assumptions are made to convert the unsteady 3D process to a steady 1D model. The principal mechanisms which Hermance put into this framework were a dominant AP-binder interfacial surface reaction, and a single premixed flame sheet in the gas. In that work however, an unrealistics description of the propellant surface was assumed and the heterogeneous reaction was assumed to occur only between the oxidizer crystals and the binder.

One of the most ambitious and famous model for the complex flame structure which furnishes the baseline for this review is proposed by Beckstead, Derr, and 
Price (the BDP model [16] in 1970), as shown schematically in Fig.1. Three separate flames can be identified in the gas phase. 1. a primary flame between the decomposition products of the binder and the oxidizer, 2. a premixed oxidizer flame, and 3. a final diffusion flame between the products of the other two flames. In spite of the BDP model is one-dimensional and necessarily omits or fails to properly account for important physics, but attempts to account for many of the significant feature of the combustion field. The influence of this work (published in 1970) still endures [17], and 1D models are still used [18]. Several improvements to BDP model of steady-state burning have been conducted. Lee et. al. [19] presented a modified picture for the flame structure for AP-Binder-AP sandwich as in Fig.1.

This sketch show the principles of the combustion zone, in which the oxidizer-fuel flames consists of a leading-Edge Flame (LEF) that stands in the mixing region of the oxidizer and fuel vapors, and a diffusion flame that trails from the LEF up to a point where the fuel vapor is all consumed. The LEF is a region of very high heat release as compared to the rest of the diffusion flames and contributes most of the heat transfer back of the propellant surface. This edge occurs because the diffusion flame can not extend all the way to the surface, the temperature there being too low. Most of the recent studies have been used the Lee at.al. model [19] as a baseline for their computations [20-24].

Recently, however, it has been recognized that multidimensional numerical simulations are possible [21] that promise deeper insights into the physics of propellant combustion. Moreover, this path, when it joins that being carved by those studying detailed propellant kinetics $[25,26]$, will undoubtedly lead to significant predictive power.

For simplicity, most of the recent studies [for example, 27-29] assumed that the diffusion flame in BDP model can be described by a Burke-Schumann flame sheet $[30,31]$, thereby discarding the importance role played by the leading edge of this flame. Jepsson et.al. in 1998 [32] show that, as illustrated in Fig. 3 the fact that differing sizes of the AP grains within the binder require different assumptions about the gas phase flame. Combustion modeling for multimodal composite propellants requires both premixed and diffusion flame theory. Fine AP sizes within the binder can be modeled as a premixed flame. Increasingly coarse AP sizes, however, approach an AP monopropellant flame, while midrange AP sizes require diffusion flame calculations.

\subsection{Solid and Gas Phases Reactions}

The basic idea for the burning of the rocket propellant is further illustrated in 1998 by Jeppson et.al. $[32,33,34]$, as shown in Fig.2. The composite solid propellant is at a given initial temperature. As the temperature increases, the AP portion of the propellant undergoes a partial decomposition. With further heating, the propellant ingredients can melt or liquefy and the condensed liquid layer forms. This condensed layer consists of many phases: solid to liquid AP, liquid HTPB, and gas phase bubbles. These bubbles contain the gaseous species formed by the semi-global condensed phase decomposition mechanism for liquid AP and 
HTPB. The temperature rises sharply as the gas phase flame develops in the third region "jump conditions".

Few decades ago, several theoretical studies on the combustion field of the burning of the heterogeneous propellant have been conducted. These researches are divided into two main categories. The first one is concentrated on the gas phase modeling without consideration for the condensed phase process, for example [11, 20-24,34]. The second one is studied the condensed phase reaction as the most important factor, for example [15,35].

Recently, few studies $[27,28,29]$ have been employed the complex coupling between the solid-phase and gas-phase process, by solving the full NavierStokes in the gas-phase simultaneously with the energy equation in the solid phase.

\subsection{Combustion Surface Topology}

During the last four decades, all the theoretical studies for modeling of solid propellants assumed that the regression of the surface function is constant with time. Moreover, most of these work assumed that the combustion surface is flat. In general these models have been somewhat successful for given good insight about the complex flame structure, but are not sufficiently accurate, or complete to predict the effect of the unsteady non-planar moving combustion surface on the burning rate and, in turn on the complex flame structure. Only the work by Jackson, et.al. [23] considered the combustion surface has a non-flat function (i.e. Hills or Valleys) and no serious attempt has been taken to advance the regression of the surface function to be dependent with time till the year 2001, Recently, for the first time, Hegab, et.al. in 2001 [27,28] developed a mathematical model that described the unsteady burning of a rocket propellant by simultaneously solving the combustion field in the gas-phase and the thermal field in the solid-phase, with appropriate jump conditions across the gas/solid interface (combustion surface). Propagation of the unsteady non-planar regressing surface is described by using a level-set formulation which gives rise to a Hamilton-Jacobi equation, as in Ref. [36].

\section{AP MONOPROPELLANT COMBUSTION MODEL}

Combustion of $\mathrm{AP}, \mathrm{NH}_{4} \mathrm{ClO}_{4}$, has been studied extensively in the past. As Guirao and Williams, in 1971 [10] proposed in their AP deflagration model in the pressure range from 20 to $100 \mathrm{~atm}$. First the AP crystal experience a phase transition from a low-temperature orthorhombic structure to a cubic structure at $513 \mathrm{~K}$. When the temperature increases to around $830 \mathrm{~K}$. It then undergoes equilibrium dissociative sublimation and degradation. The degradation results in a thin superficial liquid layer and accounts for $70 \%$ consumption of the AP crystal. The remaining $30 \%$ of the AP crystal sublimes into ammonium perchlorate acid, which subsequently undergo a sequence of chain reactions to form a premixed flame producing oxidizing products, such as $\mathrm{O}_{2}, \mathrm{NO}, \mathrm{N}_{2} \mathrm{O}$, which become the major oxidizers in the gas phase reactions. 
The BDP model [16] of the steady-state burning of (AP) composite propellants has provided a framework for various modeling efforts since its application. These efforts have been reviewed by Cohen, in 1980 [37,38]. Part of the proposed gas phase kinetic model has already been successfully applied to an AP-only monopropellant combustion system by Beckstead, M in 2000, [39] and Shusser, et.al. in 2002, [40]. This model accurately calculated burn rate vs. pressure, gas flame temperature profile, final flame temperature, and initial temperature burn rate sensitivity. Reasonable calculations were also made for the concentration profiles of the major gas phase species. Figures 3 and 4, for illustrative purposes, demonstrate this accuracy with comparisons to data collected by Boggs, [41 ] and Ermolin,[data adapted from [40]

\subsection{Dependence of Burning Rate on Pressure and Temperature}

Based on the new modified model, Beckstead in 2002, [39] have introduced the characteristics of the AP monopropellant among other monopropellants, in particular the cyclo-tretra-methyle-netetra-nitramine (HMX). Most of our understanding of combustion mechanisms has been based on AP composite propellants, and to a lesser extent HMX composite propellants. Because these two ingredients are important some of their general combustion properties are summarized in Table 1. It is interesting to note that the two compounds are very different in almost every category listed, except burning rate and exponent. The chemical composition, $\mathrm{NH}_{4} \mathrm{ClO}_{4}$ versus $\mathrm{C}_{4} \mathrm{H}_{8} \mathrm{O}_{8} \mathrm{~N}_{8}$, the melt, surface and flame temperatures and heats of formation are all very different, and yet the burning rates and exponents are very similar.

Table (1): AP and HMX properties

\begin{tabular}{|c|c|c|}
\hline & $\mathrm{AP}$ & $\mathrm{HMX}$ \\
\hline Chemical formula & $\mathrm{NH}_{4} \mathrm{ClO}_{4}$ & $\mathrm{C}_{4} \mathrm{H}_{8} \mathrm{O}_{8} \mathrm{~N}_{\mathrm{g}}$ \\
\hline Heat of formatio (Kcal/mole) & -70.7 & 18.1 \\
\hline Adiabatic flame temperature & $1405 \mathrm{~K}$ & $3278 \mathrm{~K}$ \\
\hline Melt temperature $(\mathrm{K})$ & $\sim 725.825 \mathrm{~K}$ & $553 \mathrm{~K}$ \\
\hline Surface temperature at 68 atm $(\mathrm{K})$ & $\sim 825 \mathrm{~K}$ & $\sim 750 \mathrm{~K}$ \\
\hline Burning rate at 68 atm, (cm/s) & 0.8 & 1.1 \\
\hline Pressure exponent & $\sim 0.7$ & $\sim 0.8$ \\
\hline
\end{tabular}

The relative burning rates of a large number of typical monopropellant ingredients are shown in Fig. 5. Most of these data (AP, HMX, RDX, ADN, CL-20 and HNF), are summarized in a recent paper by Beckstead, [ 39 ]. Typically HMDI (hexamethylene diisocyanate) is used to cure GAP, and TFH (tetrahydrofuran) with BAMO.

The deficiency in the BDP model [16] is its inability to predict the shape of the burn rate curve of AP propellants at high pressure. The problem arises because the simple BDP model for the AP monopropellant contains no pressure dependence heat release. The Price-Boggs-Derr (PBD) model [41] of AP 
monopropellant combustion is a more comprehensive treatment than that used by BDP. It contains pressure-dependence heat release which is deemed helpful to the high pressure dependence.

\section{SANDWICH PROPELLANT MODELS}

The detailed process of composite rocket propellant combustion are complicated by the microscopic scale of the combustion zone, the hostility of the high temperature and high pressure environment. Moreover, the complexity that arises from the unsteady non-planar moving combustion surface. During the last two decades, several theoretical and mathematical models for the combustion of rocket propellant have been employed to reduce these complexities.

In this review we will focus on the most important models that based on the BDP and PBD chemical kinetics models. The composite propellants of the AP/HTBP(Hydroxyl Terminated Poly-Butadiance) and API PBAN (PolyButadience-Acrylonitrile-Acrylic acid) are reviewed and discussed.

The sandwich geometry (but not usually periodic) has long been recognized as a useful framework in which to gain fundamental insights into propellant combustion (for example [42-46]), and a notable experimental program has been pursued for some years by Price and his colleagues in 1984 [42], Lee et. al. in 1994 [19], and recently in 1999 by Chorpening, and Brewster [47].

In the sandwich propellant, the complexities imposed by the combustion microstructure can be reduced by the use of laminate propellants, in which a sheet of fuel-binder (HTPB or PBAN) layered between two sheets of ammonium perchlorate (AP). In this case two oxidizer particles within the composite matrix are separated by a specific thickness of fuel.

The solid phase of the sandwich model includes the thermal decompositin reactions responsible for the conversion of the solid oxidizer and fuel components into gas phase species as reported by Refs. [27,28] and [48]. These components are then allowed to react with each other within the gas phase through a combination of reactions. This model allowed for various reaction mechanisms to be used in the gas phase, and for certain schemes, incorporates appropriate reaction terms for both the oxidizer monopropellant flame ( Ref. [10]) and the leading edge flames, Refs. [49,50] and trailing diffusion flames, Ref. [51]. These flames are believed to be present in the more common Ammonium Perchorate (AP) / Hydroxyl terminated Polybutadiene (HTPB) propellants. In general, the sandwich model allowed the governing equations to be solved in 2D (as opposed to 3D). Moreover, it allowed for more comparison between modeling and experimental results as we will introduce in this review.

Experimental and theoretical works by Price and his colleagues [42], Hegab, et.al. [27,28], Brewster, et .al. [45], Chorpening, B. T. and M. Q. Brewster and Chakravarthy, et.al., in 2003 [53] demonstrated that the parameters, pressure, binder thickness, binder types, surface temperature, and supply stoichiometery played an important roles in determining burning rates, flame structure, and burning surface geometry. Some of their works involved pure binder lamina (HTPB or PBAN only) and the other employed oxygenated binder lamina (the 
binder loaded with fine AP powder). A detailed review on these two classes of pure and oxygenated binders is presented as follows;

\subsection{Sandwich Propellant with Pure Binder (HTPB) Lamina}

\subsubsection{Pressure sensitivity}

As we mentioned above in this review, the coupling between the pressure and the burning rate has a direct effect of the rocket propellant combustion. As a results, in this section of the review article will focus on the change in burning rates, flame structure, and surface geometry with pressure.

Experimental work by Price et. al. [42,53] provided a photographs of extinguished surface profiles of sandwich propellant at different pressures with two pure-binder lamina thickness.

Price's experiment revealed that at low pressures result in a recessed fuel binder leading the AP, whereas high pressures result in a lagging binder which protrudes above the AP surfaces. These results were consistent with the numerical model that developed by Hegab in 2003, [46].

Dependence of the burning rate on pressure from both the experimental and numerical approaches models is presented in Fig. (6). The experimental burning rate curves of the sandwich shown in Fig. 6 fitted to $a n " r_{b}=a p^{n \text { n" power law gives }}$ a pressure exponent in the range of 0.4 to 0.6 depending upon the region of interest. This level of sensitivity is in good agreement with general composite propellant burning rate measurements.

\section{- Discrepancy}

Unfortunately, the pressure dependence shown in the experimental data is opposite that predicted by the numerical models by Brewster et al. ([45], Fig.10), Hegab et.al. [46], and Buckmaster, et.al. (54). Specifically, the pressure exponent should increase at higher pressures; the opposite trend is observed from the simulation. There are a number of possibilities for the disagreement, one of these may be related to the chemical kinetics that employed with the numerical simulation.

\subsubsection{Surface features}

\subsubsection{Effect of surface topology}

A comparison between the experimental image (the left) [45] and the computation model (the right) [36] for the structure of the flame shape and the burning surface is presented in Fig. 7. The two stoichiometric surface in both the computational and experimental images represented the two strong mixing structure (at the AP-Binder interface) each centered at $|x| \sim 0.223$ and forming the flame envelop. This comparison showed how the computational steadily surface regressing profile (at $t>5$ ) [36] is qualitatively consistent with the experimental emission-transmission composite image by Brewster, et al. (2001), [45] and also with the experimental photography for the spontaneous quench samples of 
AP/BPAN/AP sandwich that reported by Lee et al. [19]. Both theoretical and experimental results verified that conditions that gave the highest burning rates resulted in narrow smooth bands of binder in the middle with little "protrusion" of $\mathrm{AP}$ at the interface.

\subsubsection{Effect of binder width}

Binder width is important because it is the length scale for diffusive transport and represents the effects of both AP particle size and AP loading in a particulate composite propellant. The effect of binder width on flame structure and surface profile can be seen in Fig. 8. Both experimental and computational results show that for thicker binder layers the binder surface protrudes into the gas phase above the neighboring AP. The diffusion flame height (at least its stoichiometric surface template) also increases with binder width. In the far right numerical plot the flame is underventilated, with the stoichiometric level surface closing over the AP. It was found that while the stoichiometric envelope is strongly influenced by binder width it is only weakly affected by pressure.

\subsection{Sandwich propellant with oxygenated binder lamina}

\subsubsection{Burning rates}

Recently, in 2003 Chakravarthy, et.al. [53] show the variation of the burning rates of sandwiches with the matrix lamina thickness (Fine AP loaded in PolyButadience-Acrylonitrile-Acrylic acid, PBAN) at different pressures as shown in Fig. 9. In this figure, a comparison was made of sandwiches with different matrices, namely, AP/PBAN $=5 / 5$ and $7 / 3$. Data at 2.07, 3.45, and $6.89 \mathrm{MPa}$ are taken from Ref. [19]. Data at elevated pressure is measured by Chakravarthy, et.al. [53]. The AP self-deflagration rates at different pressures are shown along the left ordinate and the burning rates of matrices that undergo self-sustained burning at a given pressure are shown in the right ordinate.

The sandwich burning rates are logically expected to approach the AP selfdeflagration rate at each pressure level as the matrix lamina thickness approaches zero. However, at $0.345 \mathrm{MP}_{\mathrm{a}}$, where AP does not exhibit selfdeflagration (with the initial temperature of the sample being room temperature), the sandwiches fail to burn to completion at a finite nonzero value of the matrix lamina thickness. Three important features are noted in Figs. 9 :

1) The peak burning rates of sandwiches at elevated pressures are approximately around the same lamina thickness range of $250-275 \mu \mathrm{m}$, as in the case at lower pressures.

2) The peaks grow significantly between 2.07 and $6.89 \mathrm{MPa}$, particularly for the AP/PBAN $=7 / 3$ matrix sandwiches, as pointed out earlier, but begin to weaken as the pressure is increased to 10.34 and $13.78 \mathrm{Mpa}$. That is, the dependence of the burning rate on the matrix lamina thickness is weaker at higher pressures, particularly with the AP/PBAN $=7 / 3$ matrix.

3) The peak burning rates (around lamina thickness $250-275 \mu \mathrm{m}$ ) increase only marginally between 6.89 and $13.78 \mathrm{Mpa}$, although the increase in the burning 
rate of sandwiches with relatively thick matrix lamina $(>400 \mu m)$ is proportionate with the increase in pressure.

Price et.al. in 1981 [42], Lee et.al. in 1994, [19] and Chakravarthy, et.al. in 2003 [53] presented several sandwich quenching surfaces at lower (2.07-6.89 MPa) and higher values of pressures (10.34 and $13.78 \mathrm{MPa}$ ).

It has long been recognized that the burning rate of the rocket propellant is influenced by the propellant morphology, by the size and size distribution of the ammonium perchlorate (AP) particles.

In spite of, the sandwich models that we have reviewed used as a convenient platform on which to generate the numerical code for the complex flame structure, but much serious attempt to simulate propellant burning numerically must incorporate a packing algorithm. In another word, a strategy for defining and constructing a model of packing rocket propellant numerically was required. As a result, the current study is focused on the packing of solid rocket propellant algorithms and the propellant combustion as well.

\section{PACKING MODELS FOR ROCKET PROPELLANTS}

Fortunately, the packing algorithm is one that is of interest of several scientific fields and has been studied both experimentally and numerically. McGeary, in 1961 [54] reported a brief description of some experiments on the packing of steel shot. Bimodal packing was investigated in which spheres of diameter 0.124 in. (mesh 7) are packed with smaller spheres. The smaller spheres are defined by Table 2

Table 2: Mesh number/diameter data from Ref. [54]

\begin{tabular}{|c|c|}
\hline Mesh no. & Diameter, in. (cm) \\
\hline 7 & $0.124(0.315)$ \\
\hline 20 & $0.036(0.091)$ \\
\hline 30 & $0.026(0.066)$ \\
\hline 40 & $0.019(0.048)$ \\
\hline 60 & $0.011(0.028)$ \\
\hline 80 & $0.0075(0.019)$ \\
\hline 100 & $0.0065(0.017)$ \\
\hline
\end{tabular}

The packing volume is defined as the volume of the particles plus the interstitial volume. The packing fraction $\rho$ (the fraction of the packing volume that is particles) is measured as a function of the volume fraction of fine particles (the volume of fine particles divided by the total volume of particles); the results are reproduced in Fig. 10. When the particle volume fraction is 0 or $100 \%$, the packing is monomodal and the packing fraction is approximately 0.625 .

Higher packing fractions are achieved for bimodal packs and the greater the disparity in sizes, the greater the packing fraction. In all cases, the maximum 
occurs at approximately $30 \%$ fine, $70 \%$ coarse. The largest packing fraction implied by this data is 0.8594 .

Recently, during 2000-2007, Kochevets, et.al. [55,56] , Knott, et.al. [57], Buckmaster, et.al. [58,59], and Hegab et.al. [60] developed a random packing algorithm in order to numerically construct models of heterogeneous rocket propellants. Their packing algorithms are based on the integration of the random packing approach and the collision theory that has been described by Lubachevsky et.al. in 1990,1991 [61,62] and by Zhang et.al. in 2001, [63].

Hegab, in 2007, [66] described the disk pack model by assuming that the particles of the AP are 2D disks and distributing them in a random fashion and applied to a binary packs, distributions of disks as shown in Fig. $11 \mathrm{a}$, b, and c (a) monomodal disk pack (b) Bimodal disk back, and (c) Multimodal disk pack. The length scale is 500 microns. They added also some insight into the nature of the combustion field supported by such a propellant as in Fig. 11b. The reaction rate contours generated from the combustion is illustrated in Fig.12.

Buckmaster et. al. [64] presented a graph showed the variations of burning rate with pressure for two packs along with two sets of experimental data as shown in Fig.13. As for the upper data points: the diamonds are numerical results for a pack defined by $20 \mu \mathrm{m}$ Thiokol data, the stars are experimental burning rates for the Miller pack SD-III-88-3, which consists of $55.79 \%$ of a $20 \mu \mathrm{m}$ AP cut and $31.58 \%$ of a $0.7 \mu \mathrm{m} \mathrm{AP}$ cut; and the crosses are numerical results for a stoichiometric pack defined by Miller's data. The agreement for the small-particle packs is only achieved when the fine powder was accounted for, as shown by the difference between the 'diamond' results and the 'cross' results.

At this point we can conclude that the results that reported by . Kochevets, et.al. [54,55], Buckmaster, et.al. [64], Jackson, et.al. [65], and Hegab et.al.[60] in 2007 proved that realistic fractions of ammonium perchlorate (AP) can be packed with realistic particle-size distributions. In addition the AP size and the size distribution has a great effect on burning rate.

\section{SUMMARY AND CONCLUDING REMARKS}

The most interesting and important conclusions are summaried as follows;

1. Reviewing the compositions in microscale AP/HTPB rocket propellants, three facts are realized:

- First, mass loading of AP is typically much larger than HTPB (more than three times).

- Second, AP is a "monopropellant" and can sustain exothermic reaction without the presence of any fuel binders, which means AP is more chemically active than HTPB. In another word, for propellant containing AP, the primary diffusion flame is the combustion mechanism that dominates the determination of burning rate.

- Third, change of AP properties, such as particle size, has a marked effect on composite propellant burning. Therefore modeling of the condensed phase 
process is mostly conducted on AP. In a long run, HTPB is assumed having the same regression rates as AP.

2. Reviewing the chemical kinetics models, BDP model [16] of the steady-state burning of (AP) composite propellants has provided a framework for various modeling efforts since its application. The deficiency in the BDP model is its inability to predict the shape of the burn rate curve of AP propellants at high pressure. The Price-Boggs-Derr (PBD) model [41] of AP monopropellant combustion is a more comprehensive treatment than that used by BDP.

3. Reviewing the combustion rocket propellant models with complete coupling between the solid/gas phases with appropriate jump condition at the combustion interface, show that:-

- For the sandwich models of AP with pure and oxygenated HTPB, the parameters; pressure, binder thickness, binder types, surface temperature, and supply stoichiometery played an important roles in determining burning rates, flame structure, and burning surface geometry. In addition, laminates with the binder oxygenated by fine AP displayed a significant different diffusion flame characterstics than pure binder including a smaller flame height Unfortunately for the sandwich propellant model, the pressure dependence shown in the experimental data is opposite that predicted by the numerical models Specifically, the pressure exponent should increase at higher pressures; the opposite trend is observed from the simulation.

- In spite of, the sandwich models that we have reviewed used as a convenient platform on which to generate the numerical code for the complex flame structure, but much serious attempt to simulate propellant burning numerically must incorporate a packing algorithm. In another word, a strategy for defining and constructing a model of packing rocket propellant numerically was required at that time.

- For the 2D and 3D (disk and sphere) random packing models for the rocket propellant, demonstrated that realistic fractions of ammonium perchlorate (AP) can be packed with realistic particle-size distributions. In addition the AP size and the size distribution has a great effect on the burning rate.

In general, all of these studies gave good insight about the transient behaviuor of the burning process, but didn't reflect the acoustic instability on the large scale models that arises from the coupling effect between the burning process and the transient pressure. There are several studies have been conducted to investigate the acoustic instability on the large scale model by simulating the unsteady burning rate by a time-dependent mass injection of inert gas from a transpired side-wall. These models are not included in this review article.

\section{REFRENCES}

1. Sutton, G. P., "Rocket Propulsion Elements", 4th ed., Wiley, New York,1975. 
2. Heath M., "Whole-System Simulation of Solid Rocket: Annual Report", Center for Simulation of Advanced Rockets, CSAR, Private Communication, 1998-1999.

3. Cai, W. and Yang, V. "A Model of AP/HTPB Composite Propellant Combustion", AIAA Paper 2000-0311, $38^{\text {th }}$ Aerospace Science Meeting (2000).

4. Hart, R., Bird, R., Cantrell, R., and McClure, F. " Combustion instability in Solid Propellant Rockets", AIAA Journal, Vol. 2, No.7, pp 1270-1278,1964.

5. Culick, F. , and Yang, V., "Prediction of the Stability of Unsteady Motions in Solid-Propellant Rocket Motors", Nonsteady Burning and Combustion Stability of Solid Propellant, AIAA Progress in Astronautics and Aeronautics, Vol. 143, 1992.

6. Ferreira, J.G., Bizoi, A, and Lengelle, G. "Model for Double-Base Propellants Combustion, without and with Additives", $19^{\text {th }}$ AIAA/ASME/SAE Joint Propulsion Conference, AIAA Paper -83-1197, (1983).

7. Wu, X., Kumar, M., and Kuo, K, "A Comprehesive Erosive-Burning Model for Double-Base Propellants in Strong Turbulent Shear Flow"; Combustion and Flame, Vol. 55, 49-63 (1983).

8. Most, J., and Joulain, P., "Modeling of Normal and Erosive Burning Rate of a Hot Double-Base Homogeneous Propellant", Combustion and Flame, 105:202-210 (1996).

9. Tseng, I.S. and Yang, V., "Combustion of a Double-Base Homogeneous Propellant in a Rocket Motor", Combustion and Flame 96:325-342, (1994).

10. Huggett, G, Bartley, C., and Mills, M., "Solid Propellant Rockets", Princeton University Press, 1960.

11. Beckstead, M.W., Tanaka,M., Jing, Q., and Jeppson, M. B., "An Ammonium Perchlorate Model Based on a Detailed Mechanism," 33rd JANNAF Combustion Meeting, CPIA Publ. 638, Chemical Propulsion Information Agency, Laurel, MD, 1996, pp. 41-46.

12.Jeppson, M. B., Beckstead, M. W., and Jing, Q., "A Kinetic Model for the Premixed Combustion of a Fine AP/HTPB Composite Propellant," $35^{\text {th }}$ JANNAF Combustion Meeting, CPIA Publ. 680, Chemical Propulsion Information Agency, Laurel, MD, 1998, pp. 639-654.

13. Guiro, C. and Williams, F. "A Model for Ammonium Perchlorate Deflagration between 20 and 100 atm" AIAA Journal, Vol. 9, No.7, July 1971.

14. King, M. "Examination of Chemical Approaches to Stabilizing CompositePropellant Combustion", Journal of Propulsion and Power, Vol. 12, No. 3, May-June 1996.

15. Hermance, C.E. "A Model of Composite Propellant Combustion Including Surface Heterogeneity and Heat Generation", AIAA Journal, Vol.4 PP 16291637, (1960).

16. Beckstead, M.W., Derr, R.L. and Price, C.F., "A Model of Composite SolidPropellant Combustion Based on Multiple Flames", AIAA Journal, 8(12):22002207, (1970). 
17. Rasmussen, B. and Frederick, R.A. "A Nonlinear Heterogeneous Model of Composite Solid Propellant Combustion", AIAA Paper No. 99-2228, In $35^{\text {th }}$ AIAA/ASME/SAE/ASEE Joint Propulsion Conference, June (1999).

18. Murphy, J.J. and Krier, H. , "Heterogeneous Effects on Dynamic Burning in Composite Solid Propellant" Proceeding of the Combustion Institute, 28, (2000).

19. Lee, S., Price, E. and Sigman, R., "Effect of Multidimensional Flamelets in Composite Propellant Combustion", ", Journal of Propulsion and Power, Vol.10(6), PP 761-768, (1994).

20. Buckmaster, J., Jackson, T., and Yao, J. "An Elementary Diffusion of Propellant Flame Geometry", Combustion and Flame Vol. 117, PP 541-552, (1999).

21. Jackson, T.L., Buckmaster, J. and Hoeflinger, J. "Three-Dimensional Flames Supported by Heterogeneous Propellants", JANNAF Paper, JANNAF CS/PSHS/APS Joint Meeting, Cocoa Beach, FL. October (1999).

22. Jackson, T.L. and Buckmaster, J. "Nonpremixed Periodic Flames Supported by Heterogeneous Propellant", Journal of Propulsion and Power, Vol.16(3), PP 498-504, (2000).

23. Jackson, T.L., Buckmaster, J. and Hegab, A.M. " Periodic Propellant Flames and Fluid-Mechanical Effects", Journal Propulsion and Power Vol. 17, Number 2, Pages 371-379, (2001).

24. Jackson, T.L. and Buckmaster, J. "The Effect of Time-Periodic Shear on a Diffusion Flame Anchored to a Propellant", Combustion and Flame, 120:211221 (2000).

25. Prasad, K., Yetter, R. A., and Smooke, M. D., "An eigenvalue method for computing the burning rates of HMX propellants", Comb. Flame 115:406-416 (1998).

26. Smooke, M. D., R. A. Yetter, T. P. Parr, D. M Hanson-Parr, "Experimental and Modeling Studies of Two-Dimensional Ammonium Perchlorate Diffusion Flames," Proceedings of the Combustion Institute, Vol. 28, 329-846, 2000.

27. Hegab, A., Jackson, T., Buckmaster, J., and Stewart, S., "The Burning of Periodic Sandwich Propellants", $36^{\text {th }}$ AIAA/ASME/SAE/ASEE Joint Propulsion Conference, AIAA Paper 2000-3459, (2000).

28. Hegab, A., Jackson, T., Buckmaster, J., and Stewart, S., "Nonsteady Burning of Periodic Sandwich Propellant with Complete Coupling between the Solid and Gas Phases" Combustion and Flame, Vol. 125(1/2), PP 1055-1070, (2001).

29. Knott, G.M. and Brewster, M.Q., "Two-Dimensional Combustion Modeling of Heterogeneous Propellants with finite Peclet Number", Combustion and Flame, Vol. 121(1/2), PP 91-106, (2000).

30. Burke, S. P., and Schumann, T. E., "Diffusion Flames". Industrial \& Eng. Chem. Vol. 20, No.8, pp.998-1004 (1928).

31. Jia, X. and R. W. Bilger, "The Burke- Schumann Diffusion Flame with Zero Net Flux Boundary Conditions," Combustion Science and Technology, Vol. 99, 371-376, 1994. 
32. Jeppson, M. B., Beckstead, M. W., and Jing, Q., "A Kinetic Model for the Premixed Combustion of a Fine AP/HTPB Composite Propellant," $36^{\text {th }}$ Aerospace Sciences and Exhibit, AIAA-98-0447, Jan. 12-15, 1998, Reno, NV.

33. Ward, M., Son, S., Brewster, M. "Role of Gas- and Condensed-Phase Kinetics in Burning rRate Control of Energetic Solids", Combustion Theory Modeling Vol.2, pp293-312, 1998.

34. Ward, M., Son, S., Brewster, M. "Steady Deflagration of HMX with Simple Kinetics: A Gas Phase Chain Reaction Model" Combustion and Flame, 114:556-568 (1998).

35. Waesche, R.H. , and Wenograd, J., "Calculation of Solid Propellant Burning Rate from Condensed-Phase Decomposition Kinetics", AIAA Paper 69-145, N. Y., Jan. (1969).

36. Hegab, A.M. (2003), "Modeling of Microscale Solid Propellant Combustion"; The Tenth International Conference on Aerospace Science \& Aviation Technology, ASAT-10, May 13-15, 2003, Cairo, Egypt.

37. Cohen, N. "Review of Composite Propellant Burn Rate Modeling", AIAA Journal, Vol. 18, No.3, March 1980.

38. Cohen S. and Strand L. "An Improved Model for the Combustion of AP Composite Propellants", AIAA Journal, Vol.20, No.12, December 1982.

39. Beckstead, M. "An Overview of Combustion Mechanisms and Flame Structure for Advanced Solid Propellants", $36^{\text {th }}$ AIAA/ASME/SAE/ASEE Joint Propulsion Conference, AIAA Paper 2000-3459, (2000).

40.Jing, Q., Beckstead, M., and Jeppson, M. "Influence of AP Solid-Phase Decomposition on Temperature Profile and Sensitivity", 36 th Aerospace Sciences and Exhibit, AIAA-98-0447, Jan. 12-15, 1998, Reno, NV.

41. Price, C., Boggs, T., and Derr, R., "The Steady-State Combustion Behaviour of Ammonium Perchlorate and HMX", $17^{\text {th }}$ Aerospace Sciences and Exhibit, AIAA-79-0146, Jan. 1979.

42. Price, E., Handley, J., Panyam, Sigman, R. and Ghosh, A., "Combustion of Ammonium Pechlorate-Polymer Sandwiches", AIAA Journal, Vol.19, No. 3, PP, 380-386, (1981).

43. Price, E. "Effect of Multidimensional Flamelets in Composite Propellant Combustion", Journal of Propulsion and Power, Vol.11, No.4, July-Augest 1995.

44. Genevieve, P., and Brewster, M., "Modeling Combustion in Laminate Propellant with Fine Ammonium Perchlorate", $40^{\text {th }}$ AIAA Aerospace Sciences and Exhibit, AIAA-2002-0781, Jan. 14-17, 2002, Reno, NV.

45. Brewster, M.Q., Knott, G.M., and Chorpening, B.T. "Combustion of AP/HTPB Laminate Propellants", AIAA Paper 2001-4501, 37 ${ }^{\text {th }}$ AIAA/ASME/SAE/ASEE Joint Propulsion Conference, Salt Lake City, UT, USA, (2001).

46. Hegab, A.M. (2003), "Combustion Modeling of Micro-Structure Solid Propellant ";Engineering Research Journal ERJ, Minufiya University, Vol. 26, No.3, July 2003.

47. Chorpening, B.T. and Brewster, M.Q., " Flame Structure of AP/Binder Sandwiches from Emission Imaging", $37^{\text {th }}$ Aerospace Sciences and Exhibit, AIAA-99-0594, Jan. 11-14, 1999, Reno, NV. 
48. Knott, G. and Brewster, M., "A Two-Dimensional Model of Composite Propellant Flame Structure Burning", $36^{\text {th }}$ AIAA/ASME/SAE/ASEE Joint Propulsion Conference, Huntsville, AL, July 16-19, 2000.

49. Buckmaster, J., Hegab, A., and Jackson, T., (2000), "The Effect of Convection and Cold Probes Oscillating Edge-Flames" AIAA Paper 20000847, 38th. Aerospace Science Meeting, Reno, NV.

50. Buckmaster, J., Hegab, A., and Jackson, T., (2000) "More Results on Oscillating Edge-Flames" Journal Physics of Fluid, Vol. 12, No. 6, 2000.

51. Buckmaster, J., and Jackson, T. L., "The effects of time-periodic shear on a diffusion flame anchored to a propellant", Comb. Flame 120:211-221 (2000).

52. Chorpening, B. T. and M. Q. Brewster," Flame Structure of Wide Distribution AP/HTPB Composite Solid Propellant from Emission Imaging", $34^{\text {th }}$ AIAA/ASME/SAE/ASEE Joint Propulsion Conference, Cleveland, OH, July 13-15, 1998.

53. Chakravarthy, S., Price, E., and Seitzman, J. "Plateau Burning Behaviour of Ammonium Perchlorate Sandwiches and Propellants at Elevated Pressures", Journal of Propulsion and Power, Vol. 19, No.1, January-February, 2003.

54. McGeary, R. K., "Mechanical Packing of Spherical Particles," Journal of the American Ceramic Society, Vol. 44, No. 10, 1961, pp. 513-522.

55. Kochevets, S., Buckmaster, J., and Jackson, T. L., "Random propellant packs and the flames they support", 36th AIAA/ASME/SAE/ASEE Joint Propulsion Conference.AIAA Paper 2000-3461, 2000.

56. Kochevets, S., Buckmaster, J., and Jackson, T., and Hegab, A.,"Random Packs and their Use in Modeling Heterogeneous Solid Propellant Combustion", Journal of Propulsion \& Power Vol.17 No.4, pp. 883-891, JulyAug. 2001.

57. Knott, G. M., Jackson, T. L., and Buckmaster, J., "The Random Packing of Heterogeneous Propellants," AIAA Journal, Vol. 39, No. 4, pp. 678- 686.

58. Buckmaster, J., Jackson, T. L., Hegab, A., and Kochevets, S., "Modeling Propellants and Modeling Propellant Flames," 37th JANNAF Combustion Meeting, 2000.

59. Buckmaster J., Jackson T., Hegab A., Kochevets S., Ulrich M. "Randomly Packed Heterogeneous Propellants and the Flame They Support" AIAA paper 2001-0337, 39th. Aerospace Science Meeting, Reno, NV, 2001.

60. Hegab, A.M. and Balabel, A.E. " Effect of Ammonium Perchlorate Grain Sizes on the Combustion of Solid Rocket Propellant" Submitted to the 12 International Conference on Aerospace Science and Aviation Technology Conference,ASAT12, Military Technical Collage, Cairo, Egypt, 2007 .

61. Lubachevsky, B. D., and Stillinger, F. H., "Geometric Properties of Random Disk Packings," Journal of Statistical Physics, Vol. 60, Nos. 5/6,pp. 561-583, 1990.

62. Lubachevsky, B. D., Stillinger, F. H., and Pinson, E. N., "Disks vs. Spheres: Contrasting Properties of Random Packings," Journal of Statistical Physics, Vol. 64, Nos. 3/4, pp. 501-524, 1991. 
63. Zhang, Z., Liu, L., Yuan, A., and Yu, A. "A Simulation Study of the Effects of Dynamics Variables on the Packing of Spheres", Powder Technology, Vol.116, pp. 23-32, 2001.

64. Buckmaster, J., Jackson, T., and M. Ulrich, "Numerical Modeling of Heterogeneous Combustion", $37^{\text {th }}$ AIAA/ASME/SAE/ASEE Joint Propulsion Conference. Salt Lake City, Utah, AIAA Paper 2001-3579, 8-11,July 2001.

65. Jackson, T., Buckmaster, J., and Campbell M., Kochevets, S., and Massa, L. "The Burning of 3D Random-Pack Heterogeneous Propellant", $37^{\text {th }}$ AIAA/ASME/SAE/ASEE Joint Propulsion Conference. Salt Lake City, Utah, AIAA Paper 2001-3579, 8-11,July 2001.

66. Hegab, A.M. "Random Packing Strategy for 2D Monomodal, Bimodal, and Multimodal Heterogeneous Propellant and the Flames They Support", in press, 2007.

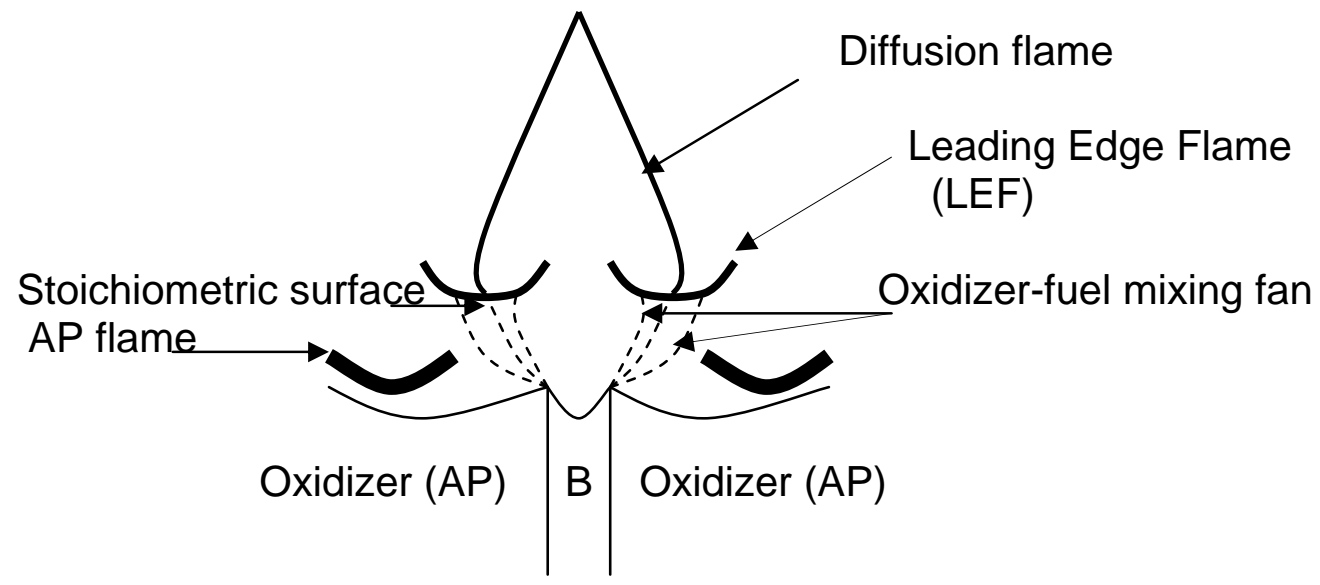

Fig. 1. Flame Structure of AP/Binder Composed Propellant Proposed by Beckstead, Derr, and Price (BDP) [16]. 


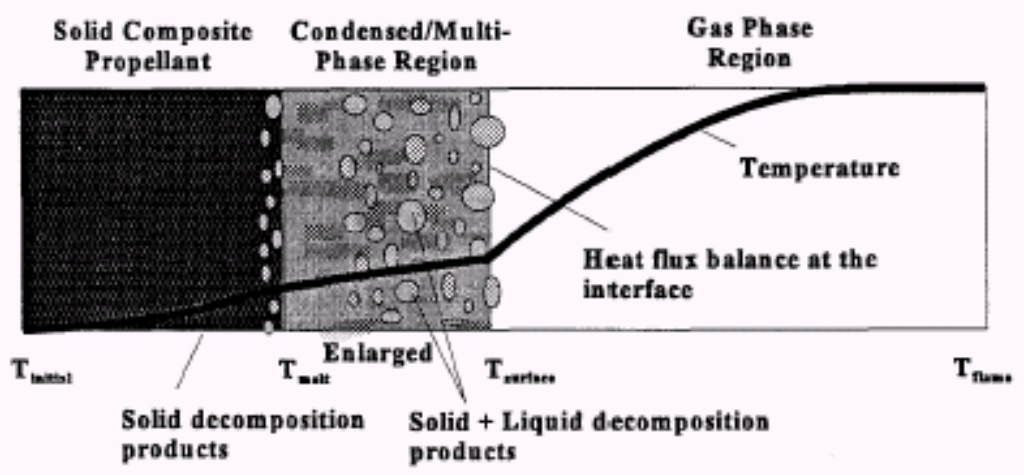

Fig. 2. The three phases of solid propellant combustion [ 32 ].

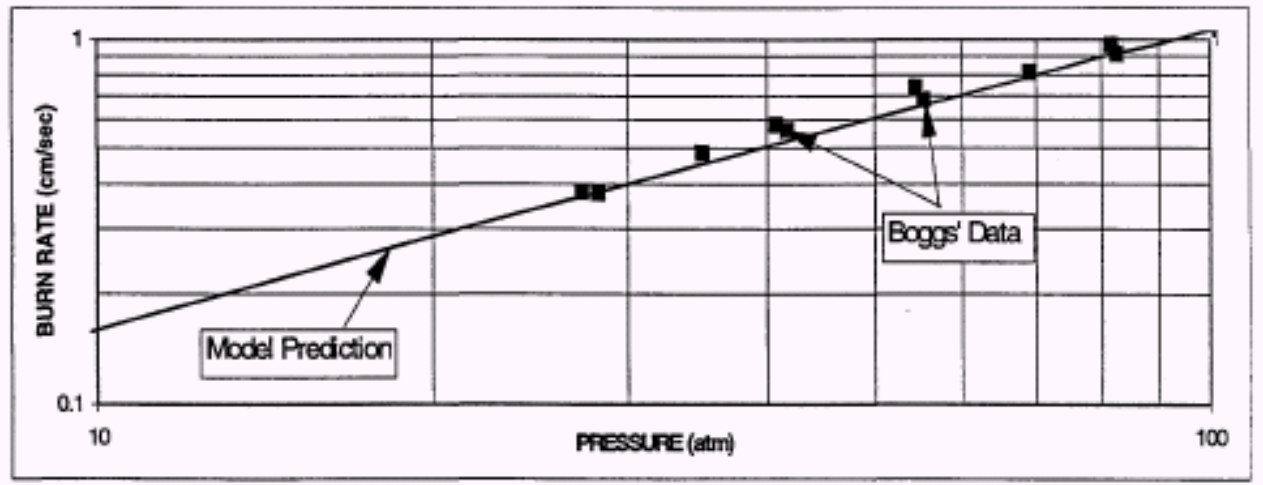

Fig. 3. Burn rate versus pressure for an AP monopropellant flame ( the model of [39] and data from Boggs[41]).

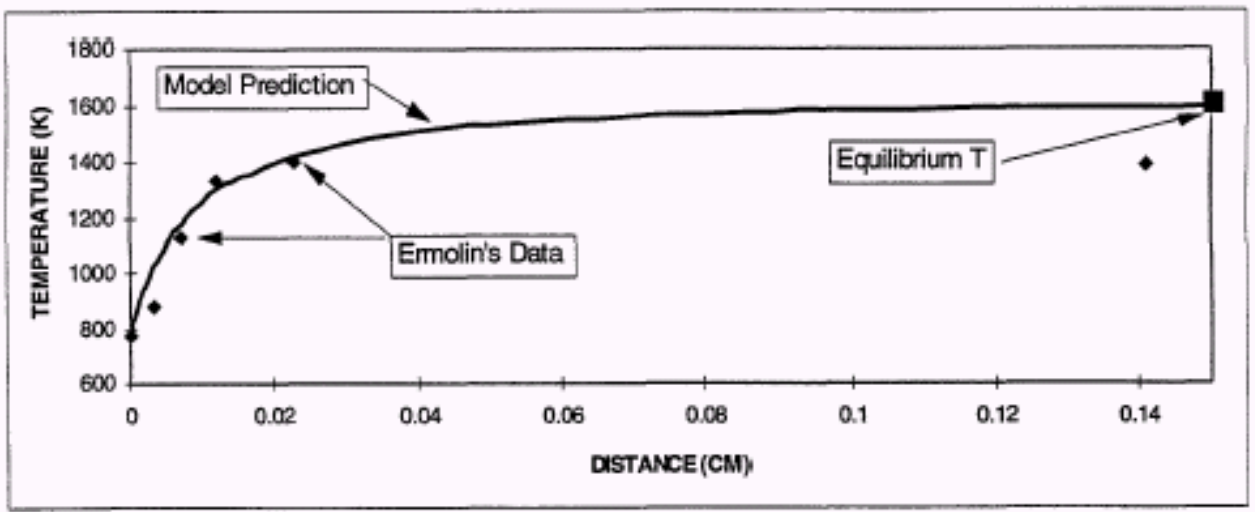

Fig. 4. Temperature versus distance from the burning surface for an AP monopropellant at $0.6 \mathrm{~atm}$ and initial temperature of $533 \mathrm{~K}$ (the model of [39] and data for Ermolin adapted from [40]). 


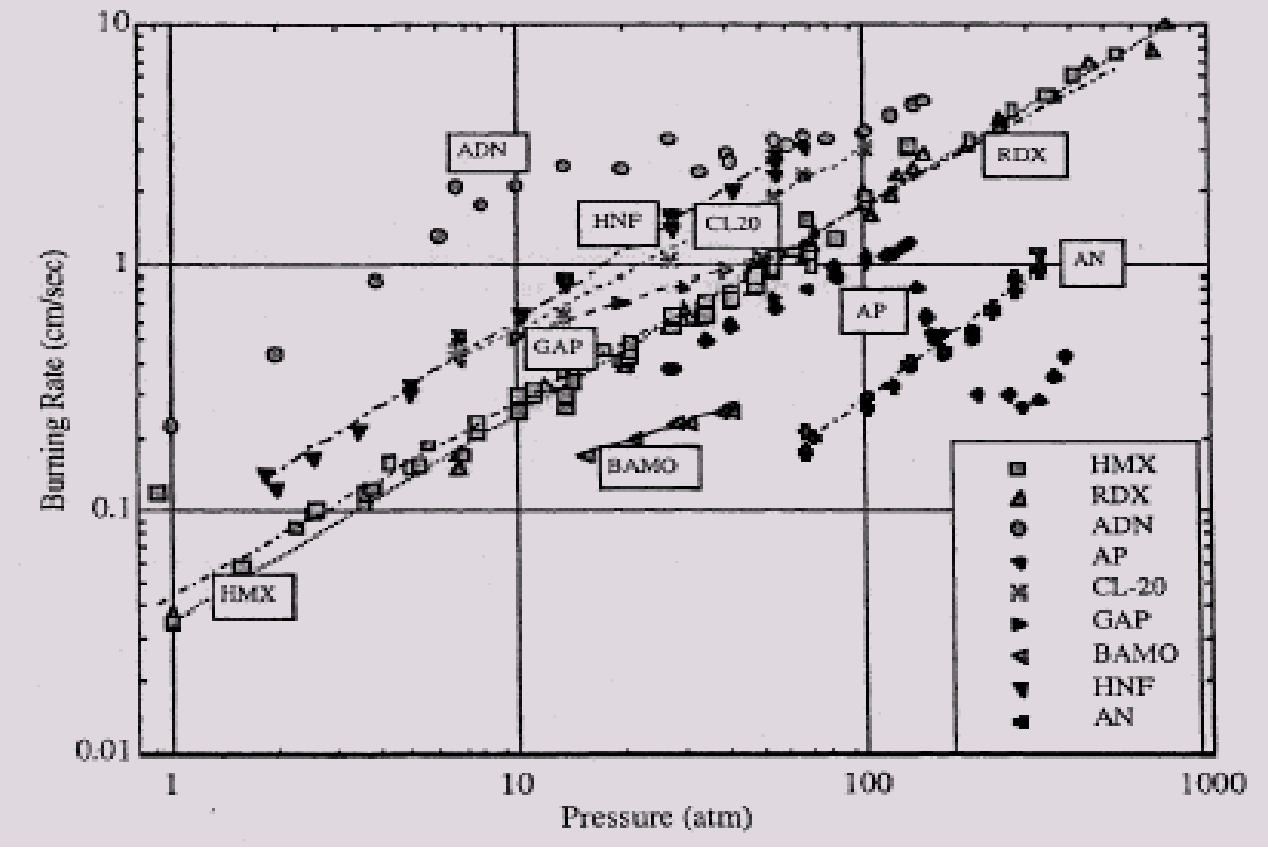

Fig. 5. Burning rate characteristics of ingredients used in solid monopropellants over a broad range of pressures. Data of (AP, HMX, RDX, ADN, CL-20 and $\mathrm{HNF}$ ), are summarized by Beckstead, [39].

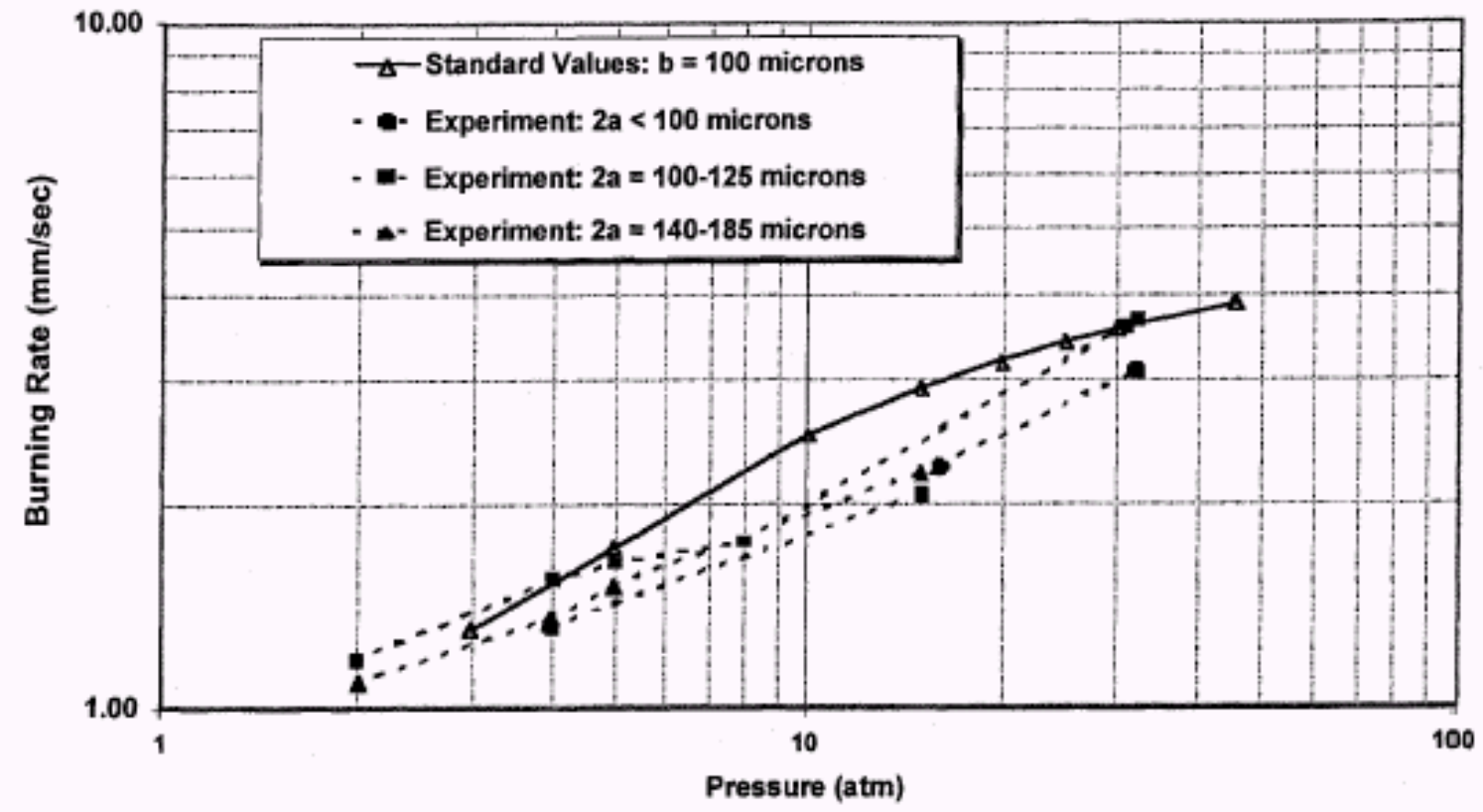

Fig. 6. Burning rate comparison, calculated (solid line, [45]) with binder thickness (b) versus experimental (dashed lines, [48), with binder thickness (2a). 


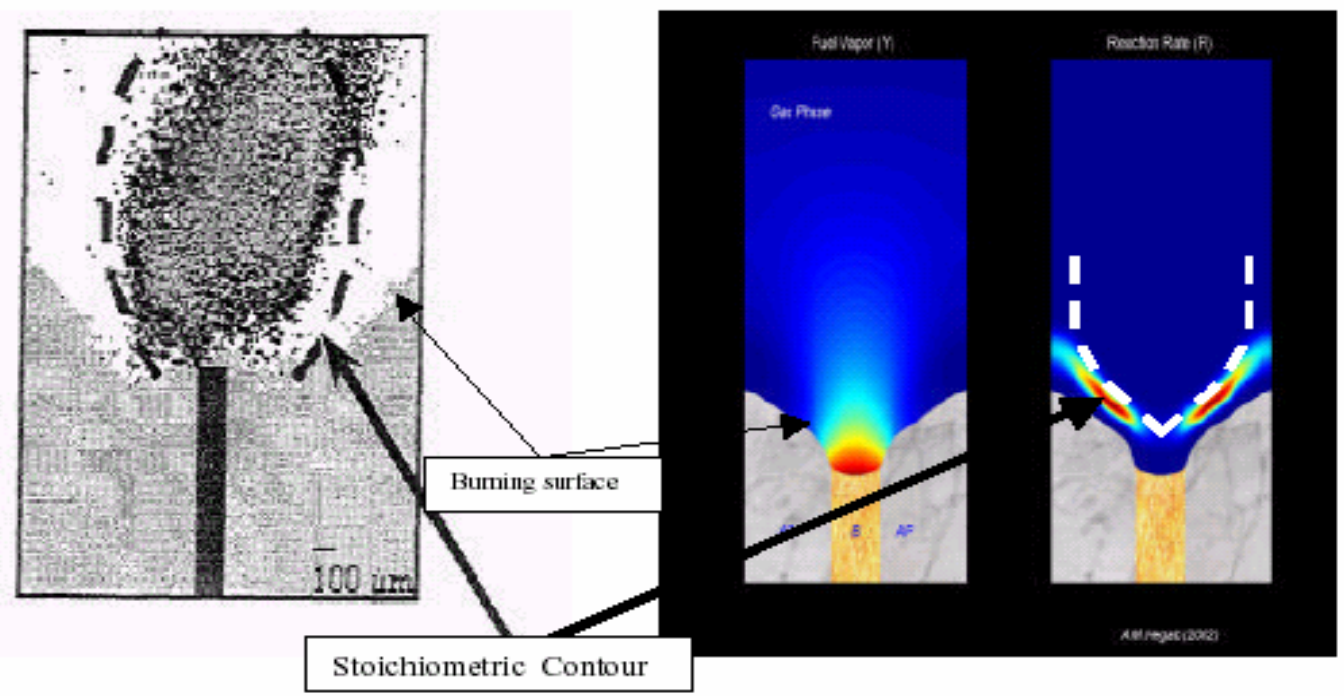

Fig. 7 Comparison of experimental image for the burning of AP-Binder-AP Sandwich [45] \{left\} with the numerical model [ 36] \{right\}.
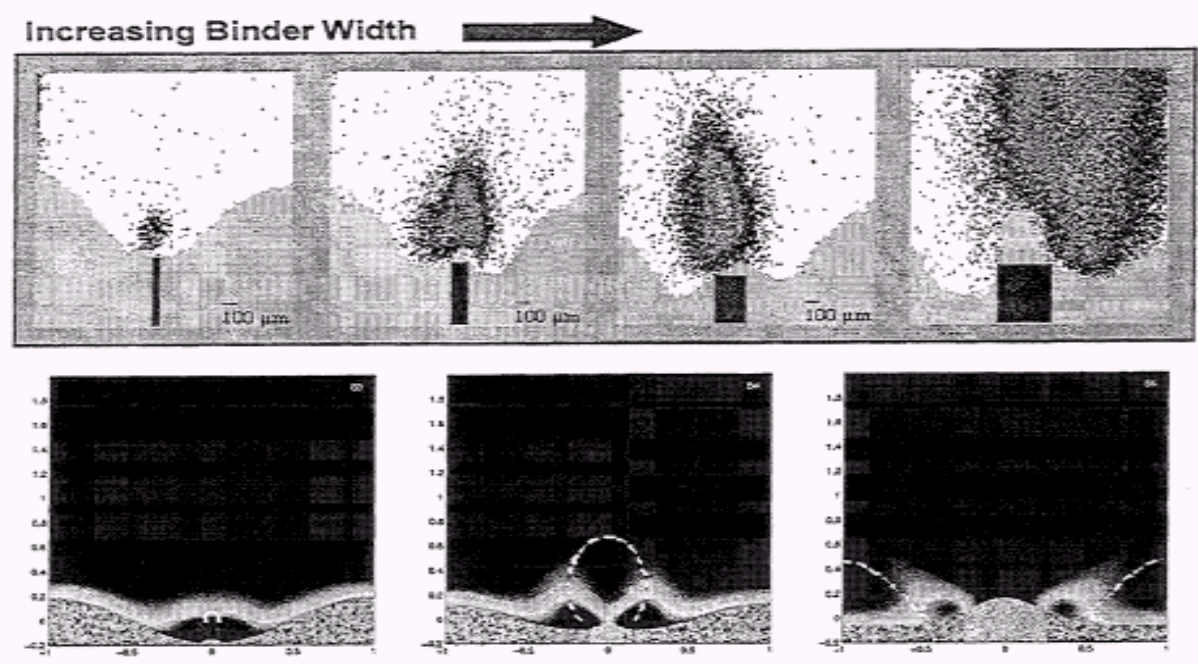

Fig. 8 Effect of binder width on flame and burning surface structure. Top row is experimental, (image adopted from Ref. [45]), bottom row is numerical, [Ref 48]. 


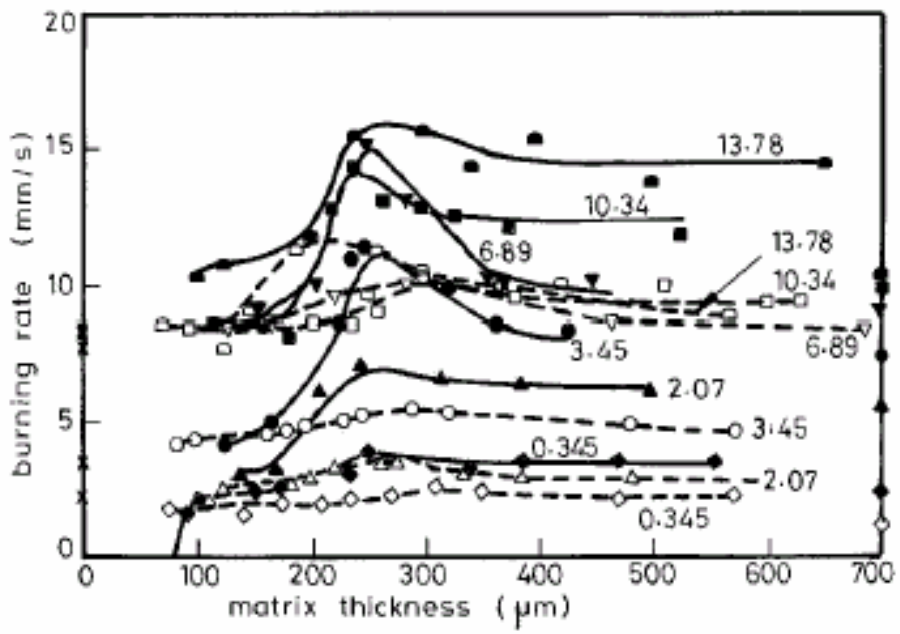

Fig. 9: Dependence of burning rate on matrix lamina thickness for sandwiches with AP/PBAN $=7 / 3$ (filled symbols and continuous lines) and 5/5 (open symbols and broken lines) matrices at different pressure levels (values noted in Megapascal); burning rates of pressed AP are shown on the left ordinate and those of matrix burning alone on the right ordinate lines. Data at 2.07, 3.45, and 6.89 MPa are taken from Ref. [19]. Data at elevated pressure [10.34 and 13.78] measured by Chakravarthy, et.al. [53].

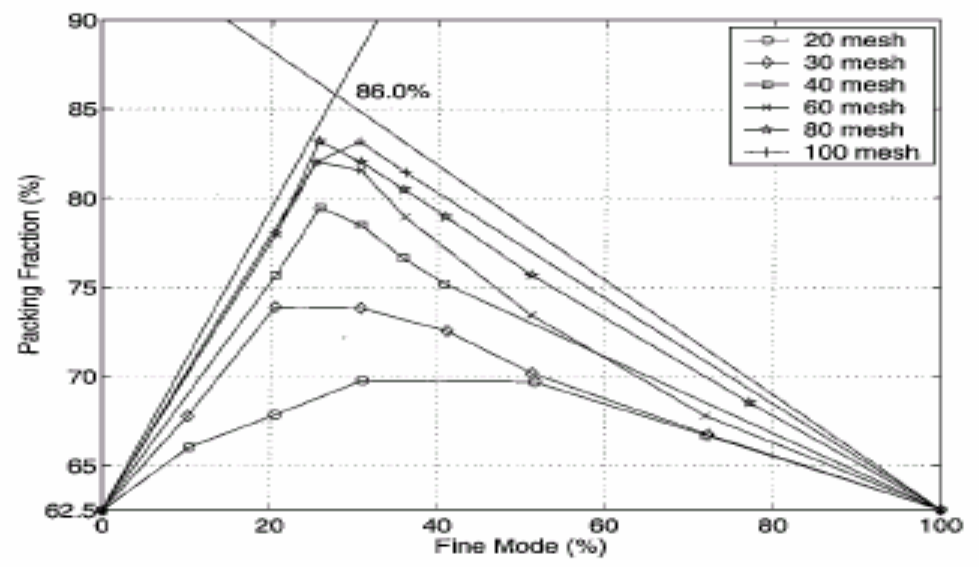

Fig. 10 McGeary's data for packing fraction [54].
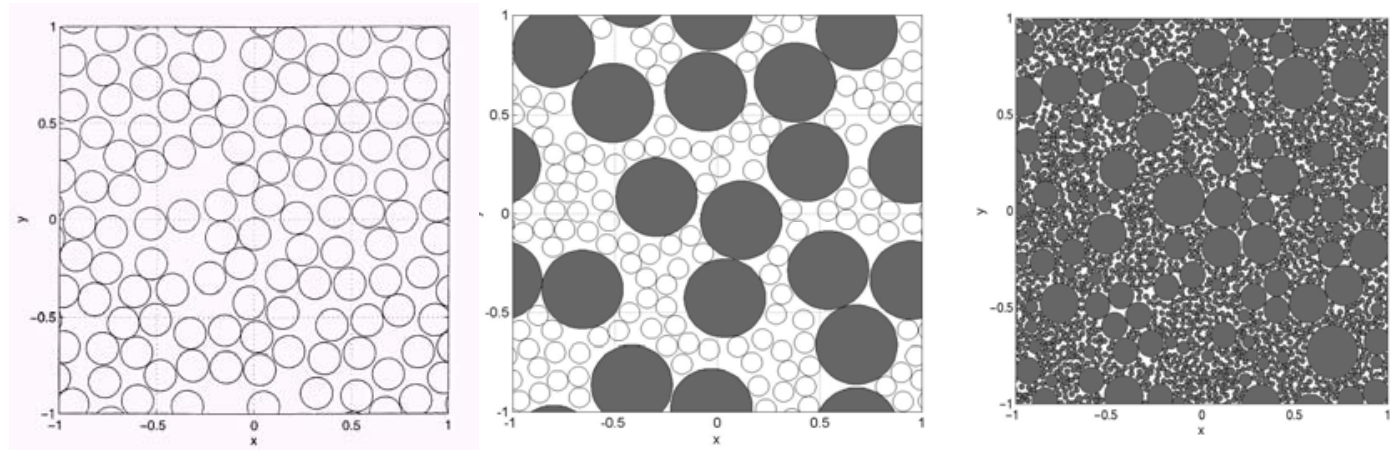
(a)

Fig.11: 2D disk pack with packing fraction 0.68. (a) monomodal disk pack (b) Bimodal disk back (c) Multimodal disk pack. Hegab, in 2007 [66]

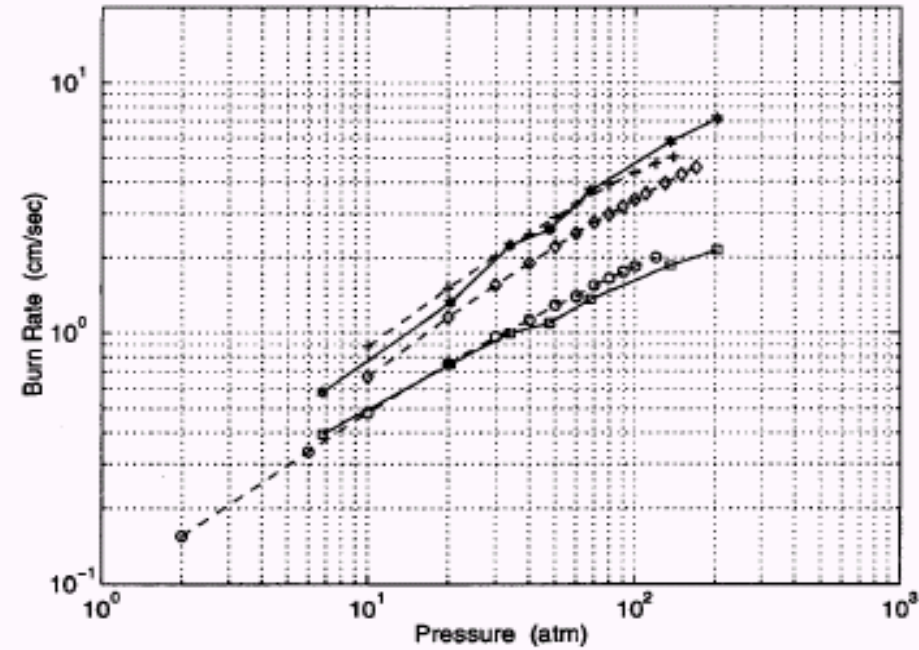

Figure 12: Burning rate variations with pressure for "lower data $\sim 200 \mu \mathrm{m}$ packs", circles are numerical, squares (joined by a solid line) are experimental. The upper data for $20 \mu \mathrm{m}$, diamonds (numerical-thiokol), crosses (numerical-Miller data), stars (experimental), Ref. [65]
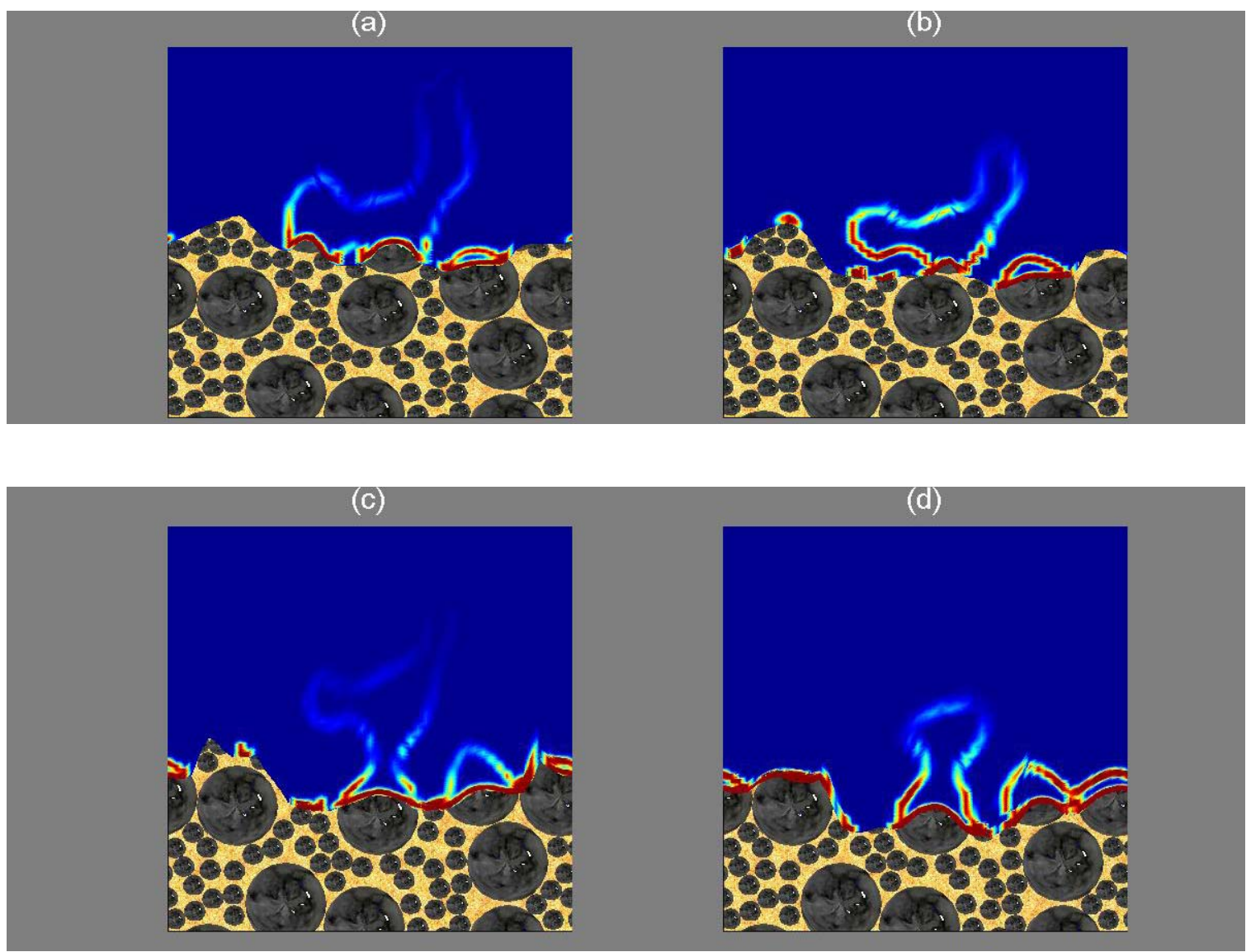


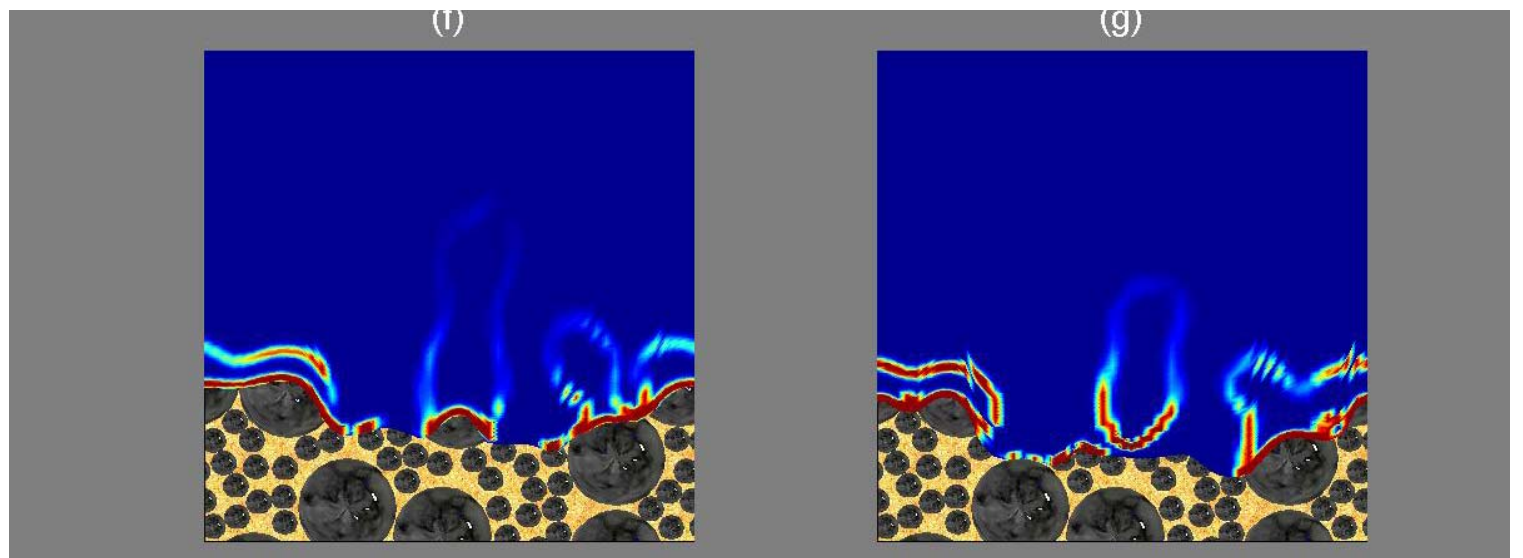

Fig. 13 Reaction rate contours above a burning "bimodal" disk-pack (Fig. 11b); at six different times by Hegab, in 2007 [66] . 